\title{
QUANDO $\mathrm{H}_{2} \mathrm{O}$ E O ESPÍRITO DA ÁGUA SE ENCONTRAM: TORNANDO VISÍVEL O ENCONTRO ENTRE MUNDOS EM PURACÉ- COLÔMBIA
}

\author{
William Andrés Martinez Dueñas - Programa de Antropologia; Grupo ACTUM-Antropologia da \\ Ciência e da Tecnologia; Universidade de Magdalena-Colômbia
}

\section{INTRODUÇÃO}

Este artigo apresenta uma reflexão sobre a minha experiência etnográfica realizada em Puracé (Cauca Colômbia), um lugar onde a água, a protagonista desta história, me abordou e, seguindo ela e suas redes, evidenciei a coexistência de múltiplas águas e seus mundos. Apesar da água ser o tema central deste artigo, o seu protagonismo na pesquisa subjacente foi determinado mediante a negociação com a comunidade indígena envolvida e pelas circunstâncias sócio-políticas enfrentadas nesse momento .

Puracé faz parte do Maciço Colombiano, uma região considerada de grande importância hídrica, pois lá nascem o Cauca e o Magdalena, os principas rios do país. Além disso, os puraceños foram envolvidos no processo tecno-científico de ordenamento da Bacia Hidrográfica do Rio Piedras que, fornece água para a maioria da população da cidade capital do Departamento de Cauca. Assim, seguir a água e as águas em Puracé também me permitiu abordar a questão das políticas ambientais em espaços onde coexistem diferentes naturezas ou mundos.

A água na Colômbia, a partir do ponto de vista antropológico, é um elemento que tem sido abordado de diferentes maneiras entre as quais se destacam, de um lado, aqueles onde o líquido é o centro dos conflitos sociais (Carreira, 2007; Rovere e Iza, 2007; Rodríguez e Orduz, 2012) e, por outro, aqueles onde é entendido como um elemento importante nas cosmologias ameríndias em relação aos seus usos (Portela, 2000; Faust, 2004a, 2004be 1990; Cayon, 2008 e 2001; Calderón, 2010). Nesses trabalhos, a água aparece como um ser mítico ou como um recurso natural, ou seja, como um elemento simbólico ou como recurso natural, isto é como um elementos simbólico ou como uma coisa (objeto) evidenciando o que Latour chamou de moderna divisão do mundo em dois domínios ontológicos, por um lado, a sociedade (cultural, simbólico, subjetivo) e por otro, as coisas (material, objetivo) (Latour, 2007 ).

Também considerei que um olhar que evite essa divisão pode ser relevante para a compreensão da água e outros elementos encontrados no meio de processos político-organizativos. Isso pode reduzir ou regular o domínio da 
episteme moderna em estados-nação multiculturais como a Colômbia, colocando no mesmo plano, o saber moderno técnico-científico com outros saberes e os mundos que estos representam, abrindo um espaço para implementar outros termos nos processos de negociação da coexistência de mundos diferentes em um mesmo território. Desse modo, este artigo tem como objetivo tornar visível o encontro entre mundos que ocorre no Resguardo indígena de Puracé (RIP) mediante os percursos que fiz nesse território junto ao Cabildo Indígena de Puracé (CIP).

\section{REDES MULTI-NATURAIS E MUNDOS NÃO(TÃO)MODERNOS}

Para falar sobre a minha experiência etnográfica e tornar evidente a supracitada coexistência de mundos, no mesmo território, adotei como um primeiro referente o conceito de multi-naturalismo, de Viveiros de Castro (2004). O autor sugere que, diferentemente do que acontece no Ocidente, cuja cosmologia distingue muitas culturas e somente uma natureza, as cosmologias indígenas da amazônia estendem a cultura a todos os seres (plantas, pessoas, animais, rios), que diferem uns aos outros, porque eles habitam naturezas diferentes com corpos diferentes. O mundo se experimenta diferente, não por ter espíritos diferentes, mas pelo corpo que esses espíritos ocupam. De tal forma que um elemento do mundo é visto e usado de acordo com o corpo que ocupa. Assim, os usos e representações não são culturais, senão materiais (Viveiros de Castro, 2004). Apesar de que o multinaturalismo ameríndio é inter-espécies (humanos, jaguares, anacondas), neste artigo, assim como fez Blaser (2009), se aplica intra-espécie (humanos).

Então, no interagir de dois sujeitos não necessariamente entram em relação culturas diferentes (formas de interpretar ou representar a natureza), mas diferentes naturezas, ou seja, todas as entidades humanas e não-humanas e suas regras particulares de interação. A partir dessa idéia, entendo mundo como um coletivo específico, que inclui todos os humanos e não-humanos possivéis e, as regras de interação entre esses que aparecem ao observador que segue uma rede ou as conexões entre os diferentes elementos desse coletivo . Este conceito evita a visão moderna, baseada na dicotomia entre a natureza e sociedade, e entre sujeito e objeto, oferecendo a categoria não-humanos, que inclui muitas outras entidades além de aquelas comprendidas na categoria moderna de "natureza", restrita aos objetos (Latour, 2007 e 2004a). Assim, o que para os modernos é um elemento da natureza (H2O), um objeto, para a visão de um não-moderno esse elemento pode conter características que os modernos consideramos exclusivas dos humanos, por exemplo, a vontade, a razão ou espírito (e.g. a água em Puracé). Na pesquisa, na qual este artigo se enquadra, o coletivo central, "o mundo puraceño", se coletou através dos percursos pelos abastecimentos de água e documentos sobre os planos de ordenamento locais , não focou as coleções mitológicas antropológicas. As coletividades de humanos e nãohumanos permitem aos modernos representar o que percebemos de outros mundos, tentando respeitar as suas próprias regras de interação. Este é um trabalho que, como observado por Latour (2007), e evidenciado por Descola (2005), tem sido adiantado por antropólogos, embora para eles, alguns desses coletivos não modernos são mito, crença ou religião.

Uso o conceito não[tão]modernos para referir aos mundos ou naturezas-culturas (coletividades) locais que não se atribuem, inteiramente, ao mundo moderno mas também não podem ser entendidos como intocados por ele. Puracé, ou mundo habitado por puraceños, é não[tão]moderno na medida em que maneiras fundamentais para definir o mundo para os modernos (cf.Latour, 2007; Descola, 2005) não ocorrem, em geral, na vida cotidiana dos puraceños. Duas das 
dicotomias fundamentais da modernidade, natureza/cultura e sujeito/objeto, não são generalizadas no momento de interação dos humanos com os não-humanos.

A água, um dos protagonistas desta história, entidade que para os modernos é um objeto ( $\mathrm{H} 2 \mathrm{O}$, um nãohumano, sem interioridade, espírito, vontade, ou cultura), para muitos Puraceños, como mostrarei mais adiante, tem características tanto de objeto (é mineral inerte e inanimado) quanto de sujeito (tem espírito e vontade), convirtiendo-a em uma entidade particular que não existe na episteme moderna, uma vez que entende o mundo através de uma divisão precisa entre o sujeito (humanos) e objeto (entidade viva ou não viva sem subjetividade, vontade ou cultura)(cf. Latour, 2007), a água é, para os modernos, apenas objeto (H2O sem espírito, subjetividade ou vontade). O fato de que esta dicotomia não proceda em outros mundos (concebidos para os modernos como culturas) é entendida como mito e como falta de conhecimento objetivo da natureza.

\section{KOKONUKOS E O CABILDO DE PURACÉ}

Este trabalho foi desenvolvido no Departamento de Cauca, no sudoeste da Colômbia, esse território é reconhecido por sua diversidade cultural, possui nove grupos indígenas, uma população mista de aproximadamente 250.000 pessoas que equivale a 22\% da população total do Cauca (DANE, 2007). Este departamento, também apresenta alta diversidade de ecossistemas, com três ecorregiões: Andes, Amazônia e Litoral Pacífico, que abrangem zonas climáticas entre 0 a 4700 m.s.n.m. Essariqueza, está no meio de uma história, ainda vigente, de décadas de conflito pela terra e seus "recursos naturais", tornando-se em um complexo território, com diferentes formas de integração à modernidade e aos processos globais de desenvolvimento (cf. Gow, 2008).

Especificamente, o trabalho de campo foi realizado no Resguardo indígena de Puracé (RIP), em companhia do Cabildo Indígena (CIP). Visitei este território, durante mais de uma década com diferentes interesses, académicos e não acadêmicos. No entanto, a pesquisa aqui apresentada começou em 2009 mediante a realização de alguns eventos de negociação com o Cabildo, precedidos por minha participação, em 2008, como colaborador em um projeto sobre a implementação de Tecnologias da Informação e Comunicação em comunidades indígenas de Cauca. A maioria do meu trabalho com o CIP foi concentrada em 2009 e 2010. O RIP, está localizado acima de 2.000 m.s.n.m., no chamado Macizo Colombiano o qual abrange as bacias dos rios Magdalena e Cauca, os mais importantes do país. Dada a importância ecológica da região, criaram-se várias áreas de conservação estatais, salientando o Parque Nacional Natural Puracé cujas terras confinam e se sobrepõem ao RIP.

No caso deste trabalho, há que destacar duas estruturas organizacionais importantes dentro do RIP. De um lado, as Juntas Comunitárias de aqueduto, que são responsáveis por garantir a manutenção e gestão dos aquedutos e abastecimento de água potável. De outro, os Comitês de Educação e Saúde que trabalham temas de interesse específico para a comunidade, a fim de assessorar ao CIP. O Resguardo, é de origem colonial, ou seja, têm antecedentes a partir do final do século XVI, no entanto o reconhecimento legal remonta ao século XIX (Tocancipá-Falla, 2008). No RIP, como em todos os Resguardos na Colômbia, a propriedade é coletiva, onde cada família recebe um pedaço de terra em usufruto (CRIC, 2009). 
O CIP é subordinado à etnia Kokonuko, para eles a água desempenha um papel central em seu mundo, não apenas como um recurso natural, mas como um ser social não-humano. De acordo com Portela (2000), para as comunidades indígenas das montanhas do sudoeste colombiano a água é um ser central que informa as dinâmicas simbólicas e materiais dos povos Coconucos, Guambianos, Paeces e Yanaconas. Aágua, para esses grupos é viva, não inerte como para os modernos, determinando uma relação de reciprocidade "harmônica", onde seus usos não só focam a agrícultura e o doméstico, mas também os processos de saúde-doença, sendo um elemento de grande relevância nas práticas de cura pelo seu poder espiritual. Faust (2004a, 2004b), evidenciou a centralidade da água nesse povo que se consideram “filhos da mãe água”, cuja personificação é um ser antropomórfico conhecido como Mama Dominga; a água também "reflete o caráter dialético desse pensamento [Coconuco]". Como Portela, Fausto (2004a) mostra a dialética frio/quente, que reflete o nível energetico da água, morna ou fria, corrente ou estagnada, que determina os usos desse líquido.

\section{ABASTECIMENTOS DE ÁGUA: DO SERVIÇO PÚBLICO AO ESPÍRITO DA ÁGUA}

Os protocolos estabelecidos pelo Cabildo Indigena de Puracé, e por outras organizações indígenas do sudoeste da Colômbia, no tocante à liberação de pesquisas, como a que deu origem a este documento, indicam que o proponente deve apresentar seu projeto diante do Cabildo, órgão responsável pela discussão sobre a conveniência e decisão sobre a permissão para a sua realização.

Atendendo esse procedimento, em maio de 2009, apresentei o meu projeto diante dessa autoridade. Lá apresentei a minha proposta, enfatizando o meu interesse em explorar os processos de implementação de políticas ambientais enquadradas no desenvolvimento sustentável (DS), à luz do conceito de multinaturalismo (Viveiros de Castro, 2004). Mostrei ao comitê que queria fazer a minha análise a partir da possibilidade de coexistência e interação de múltiplos mundos, com particular interesse em explorar o que havia produzido dita relação. Aceitando a minha proposta, o CIP propôs que integrasse o grupo que estava discutindo uma nova proposta estatal de privatização do recurso hídrico, os planos departamentais de Água (PDAs), (CONPES 3463, 2007). Isso, orientou a minha pesquisa para a questão da água e determinou que os percursos constituissem o principal método de pesquisa.

\section{PERCORRENDO OS ABASTECIMENTOS}

Os percursos são os monitoramentos que faz o CIP, mediante os comuneros ou cabildantes, à pesquisadores ou funcionários que visitam o Resguardo para inspecionar ou prospectar atividades relacionadas com obras públicas, meio ambiente e atividades de pesquisa. Esse método permite, mediante caminhadas de reconhecimento da região ou especificidade que se espera examinar (e.g, abastecimentos de água), realizar um diálogo com os responsáveis pelo acompanhamento do visitante interessado em um aspecto particular do Resguardo, e também entrevistar-se com outras pessoas que surgem no desenvolvimento dos percursos. Este método, me permitiu evidenciarar as redes entre mundos, onde os seres modernos e não-modernos se conectam, desde as bactérias até o espírito da água, passando pelas vacas, pelos comuneros e engenheiros. 
O percurso começa na vereda ou no local de moradia e finaliza na fonte de água que, em alguns casos, são nascentes ou manantiais. Neste processo, se avança pelos tanques de armazenamento de água e sistemas de tubulação que transportam a água do seu ponto de armazenamento para as moradias e outros locais onde é necessária a água potável, como os bebedouros para o gado.

Durante os percursos, a conversa com o acompanhante foca inicialmente aspectos históricos, técnicos, financeiros e organizativos. Especialmente, são relatados os problemas orçamentários e o modo como a comunidade, mediate um esforço coletivo, tem mantido os abastecimentos de água durante décadas. À medida que nos afastamos das moradias aproximamo-nos da fonte de água (manancial), geralmente localizada em locais altos e com precença significativa de vegetação nativa ou de reflorestamento. Ali econtra-se "o isolamento", um segmento de terra cercada com arame farpado, como proteção do gado, onde é permitido o desenvolvimento livre da vegetação nativa e árvores que são considerados bons para atrair à água. Neste lugar, fala-se do aforo (litros de água por unidade de tempo) que fornece o nascimento e de quanto é aproveitado para o fornecimento, entre outros elementos técnicos relacionados com os cuidados desse lugar.

Nas nascentes de água, são importantes os aspectos técnicos da construção de barragens e reservatórios, mas tambem aquelas questões cuja lógica não obedece aos manuais modernos de manejo da água. Nesses lugares, a água ou o espírito de água entra em um conflito particular com o concreto das barragens e tanques. Isto deu lugar a um ajustamento entre a organização técnico-científica da água $\left(\mathrm{H}_{2} \mathrm{O}\right)$ e o espírito da água, que determina a construção e utilização do sistema hidráulico em Puracé.

Nesses lugares, me explicaram por que alguns tanques não estão localizados perto da nascente de água, mas a poucos metros ou fora da área de isolamento. Albeiro Catuche, comenta que o dono da terra onde se encontrava a nascente de água, não autorizou a construção do tanque de concreto perto do manantial porque a água não gosta de concreto e foge. Por isso, o abastecimento de água para a vereda xi Pululó foi construído a uma distância prudente:

"Eles [os avós] costumavam dizer que em uma nascente de àgua nunca se construia um tanque de cimento porque supostamente a água fica enterrada, muitas pessoas dizem que a àgua se seca, mas supostamente não é verdade que água se enterra, se vai por outra rota, ou seja, é como se não a impactasse [agradasse] muito que constroam essas coisas muito próximas. Por isso, aqui o proprietário deste lote protestou, disse: como iámos construir tanques aqui tão perto. Ele dizia: vão fazer fugir a água, a água vai secar ... ele não deixou que o tanque fosse construído aqui [nascente de água]”. (conversa com Albeiro Catuche, Pululó, 6 de Abril de 2010)

Na vereda de Tabio, a nascente de àgua está localizada na borda de um penhasco, por isso, o tanque está localizado sobre o manantial. Giraldo Yacumal, contou que o falecido Eladio Garcés, comunero reconhecido pela sua expertise em construção de aquedutos, fez um ritual antes de iniciar a construção do aqueduto e quando ficou pronto mandou rezar uma missa: 
'Há que pedir permissão, nós aqui, com o falecido Eladio, ele sabia de tudo, tivemos que pedir permissão, nós viemos e falomos lá no ... [aponta para a nascente de água], onde nós construimos o tanque; ... ele fez uma oração lá e pediu permissão para ... Todas essas árvorezinhas, já estavam lá e nos deixamos alí quetinho, isso é um cuidado enorme que há que se ter com um olhinho de água, não pode chegar e pegá-lo à força, não, porque os olhinos têm as suas histórias ... aqui nem barulho fizemos, nós não fizemos nada disso, isso é algo que ele nos ensinava, aos olhinhos não pode alcançálos o ruído, ... aqui foi com muito cuidado, porque os olhinos [de água] tem história."

Quando a água fugiu ou se aprofundou porque foram construídas estruturas de concreto perto das nascentes se pode oferecer um presente ao manantial para que o vertedero retorne. Na vereda El Alto de Anambio, Francisco, o presidente do aqueduto, está realizando um tratamento especial a um nascimento onde a água se enterrou porque foi construído o tanque de cimento perto dele. Este tratamento implica em presentear a a água, neste caso, dar-lhe uma planta (repolho ornamental) com rapadura. Francisco nos mostrou as plantas que haviam sido plantadas e como depois disso a água tinha aumentado um pouco ou voltado a surgir onde nascia antes que o tanque fosse construído. Francisco disse assim:

“Acontece que por desconhecimento se constroi o tanque pertinho do nascimento. Então, um homem de Chapio já velho disse que 'esse trabalho ficou ruim, com o tempo a água vai diminuir, vai aprofundar'. Eu disse a ele pode ser ou não. Parecia que ele tinha ausência de credibilidade na crença ... com o tempo a água se enterrou, e veio aqui embaixo, e ficou pouquinha água, meia polegada ... Uma pessoa me aconselhou e dize-me semeá-lhe umas plantas e dâ-lhe alguns arbustos e com rapadura. Então, eu fiz isso, meio que em segredo, sim?. Passado o tempo, a água pode voltar a subir quase ao nível do nascimento ... Semeiou apenas umas quatro plantas, mas com fé e vontade e, com a esperança de resgatar a água, certo? Então, sim, com o tempo, a água foi subindo, tem galgado, sai alí, porque a água não vinha aqui, saia lá embaixo, então já subiu quase ao nível ... O tanque não deveria ter estado lá, se tivéssemos construído lá de fora e depois canalizado, não tinha problema nenhum.” (conversa com Francisco, Alto Anambio, 16 de maio de 2010)

Aágua que é descoberta em Puracé, através dos percursos nos abastecimentos, é uma entidade difícil de definir a partir da perspectiva moderna. Alguns Puraceños dizem que a água tem um dono, como montanhas ou florestas, outros dizem que tem espírito, outros que dono e espírito são o mesmo. De todo modo, há uma quantidade grande de relatos e práticas que falam e interagem com este dono/espírito da água e os efeitos que produz.

\section{O DONO/ESPÍRITO DA ÁGUA}

Percorrer os abastecimentos me conduziu desde a água como um serviço público, passando pela organização comunitária necessária para mantê-lho, até o espírito/dono da água. Esse espírito, não só determina como se deve tomar a água, mas deixa rastros de sua presença e ação mediante doenças nas pessoas. Viveiros de Castro (2004), menciona que os espíritos donos dos animais são uma noção comum em comunidades indígenas sudamericanas, que lhe confere características de sujeito animal, permitindo relações intersubjetivas humano-animal. No caso deste artigo, o espíritodono é associado com a água, que tem características de animal, de coisa e de sujeito. 
Por exemplo, um comunero de Tabio sofre de epilepsia porque quando jovem caiu no rio San Francisco; o espírito da pessoa fica vulnerável porque cai assustado no rio e o espírito da água tomá-lhe e atormentá-lhe esporadicamente. A luta entre os espíritos traz epilepsias.

Em Tabío, as professoras da escola comentam que são muito cuidadosas para não deixar seus filhos se aproximarem dos olhos de água, porque o ar que sai de lá assusta às crianças e os adoece. É também, o lugar de moraria do duende, um não-humano antropomórfico -com aspecto de criança-, poderoso e buliçoso que gosta de brincar com as crianças. Também comentam que a água das nascentes, colhida com grande respeito e tratada pelo médico tradicional cura o susto:

'No meu caso, ... eu sou muito cuidadosa ... A pessoa sente medo de ir aos olhinhos de água com eles [as crianças], porque, pois, dizem, não é? Que lá está o duende ... ou seja, não é tão bom o olhinho de água. Então, eu fico com medo de levar meus filhos, eu prefiro ir sozinha ou como eles dizem, se você vai levar a menina levá-la pela mão, não a deixe sozinha, porque pode ser que ela desapareça ou que o duende carregue ela. Então, eu fico sim, com certo receio, eu prefiro ir sozinha, ainda que eu sinta temor de estar lá”. (Conversa com a professora da Escola Tabio, 19 de março de 2010)

Algumas pessoas fazem alguma preparação antes de ir para os olhos de água ou depois de visitá-los, buscando proteger-se do espírito da água ou do duende.

"Quando a gente vai no olhinho da água, seja para limpar ou ver, a gente têm que aplicar-se os remédios que fazem os médicos, remédios de espírito, que são os colchetes. Então, com isso a gente se protege ... ou quando a gente retorna de sahúma se limpa com arruda ou absorve o cheiro desses remédios, ou bebe e pronto. Especialmente, quando a gente vai com as crianças ou então mesmo quando só vai ficar perto do olho de água, há que limpar as crianças, especialmente, quando há muito vento.” (Conversa com professoras de Tabio, 19 de março de 2010)

Aágua da nascente é usada, pelos médicos, em diferentes tratamentos:

“...Aqui, por exemplo, há médicos tradicionais que trabalham com esse assunto. Como fazem? quando as crianças são pequenas, de messes, recem nascidos ... eles se assustam, então a gente, a nossa tradição é levá-los onde um médico tradicional, certo? A gente não vai diretamente ao médico, a gente diz, a criança está assuntada, a criaça tem alguma coisa. Ou seja não é de medicamentos, é preciso consultar o médico tradicional. Aqui nós temos médicos, então, pessoalmente, eu consulto eles. Então, por exemplo, a minha menina, a mais velha, quando ela nasceu, ela nasceu assustadinha. Então, nós visitamos um médico tradicional. Por exemplo, temos o médico do Seis, Henry Garcés. Ele trabalha muito com a água, o que ele faz? Por exemplo, eu levei a menina lá e ele me disse para ir pegar àgua no olhinho. Pediu em torno de um litro de água e deu uns remédios que ele preparou. Diz, mergulhe-os, mexa bem e faça um banho na menina, com isso o susto que ela tinha adquirido vai embora. Então, nós usamos a água na parte tradicional." (conversa com uma professora, Tabio, 19 de março de 2010) 
Percorrer os abastecimentos foi um método eficaz para navegar no mundo puraceño, em constante expansão, mistura e mudança. Foi possível experimentar que, em uma nascente de água coexistem a gravidade, o espírito da água, engenheiros, comuneros, ambientalistas e vacas. Um abastecimento de água não é apenas uma rede de condução hídrica: é uma rede de mundos e tempos. Isto contrasta com a idéia de água como um serviço público nos Planos Estatais de Privatização da Água (PDAs). Por isso, em Purace, a implementação dos PDAs teve de passar por vários processos de análise no CIP.

\section{ABASTECIMENTOS DE ÁGUA E ORGANIZAÇÃO COMUNITÁRIA EM PURACÉ}

Percorrer os abastecimentos de água também me permitiu ver como as políticas ambientais são transformadas localmente. Os abastecimentos de água em Puracé surgiram como uma iniciativa estatal, liderada pelas Secretarias de Saúde, no âmbito dos programas de saneamento. Essa política desdobrou-se na construção de aquedutos locais, em parte, graças à coordenação e financiamento das administrações territoriais (prefeituras e governações). Finalmente, os aquedutos ou abastecimentos tornaram-se uma prioridade para as comunidades locais e remplazaram o sistema de abastecimento de água através de canais. Isso tem permitido a implementação de estratégias político-organizativas para a construção e manutenção dos abastecimentos de água, entre as quais se destaca a minga (trabalho coletivo para a comunidade) e as Juntas de aqueducto.

Os abastecimentos de água não são apenas a implementação da idéia moderna de água en Puracé. Há uma transformação e uma dinâmica específica diferente em termos da forma como se faz e do que representam para a comunidade. Além disso, essas redes de água conectam os não-humanos que habitam Puracé, como o espírito da água, com elementos modernos como a água $(\mathrm{H} 2 \mathrm{O})$ potável. Por exemplo, a construção de barragens e reservatórios de abastecimento de água é determinada pelo espírito da água, que não gosta de concreto. Os fechamentos, isolamentos ou locias de reflorestamento nas nascentes de água obedecem, simultaneamente, à várias lógicas: evitam a contaminação pela entrada de gado às fontes de água; são lugares onde as entidades estatais têm incentivado o reflorestamento para garantir a permanência de fontes de água, são lugares habitados pelo espírito de água e por el duende e, também fontes de água para remédios de espírito. Isso não significa que toda a comunidade puraceña partilhe das concepções sobre os isolamentos das nascentes de água, mas também não são práticas e saberes raros.

Os abastecimentos de água, podem entenderse como um ajuste entre os diferentes mundos e seus atores, um pacto implícito que, até agora, respeita a autonomia territorial indígena. Porem, de não tornar-se evidente ou explícito, pode levar a uma transformação radical da água em Puracé deixando morrer seu espírito e tornando-a como um mero recurso. A idéia de purificação, não só elimina as bactérias do mundo moderno também pode eliminar o espírito da água. As tubulações não somente conduzem a àgua, conduzem um mundo, o que cria espaços de encuentros e ajustes ontológicos; vejamos um caso.

Nos últimos anos, os sistemas de abastecimento têm sido mantidos e melhorados, por vezes com o apoio das administrações municipais ou departamentais e outras, mediante iniciativas locias ou do Cabildo. Recentemente, essa 
estabilidade foi perturbada por um projeto, liderado pelo Estado, chamado Planos Departamentais para o Manejo Empresarial dos Serviços de Água e Saneamento (PDAs) . Isto é parte de um esquema maior: a modernização empresarial do Estado (CONPES 3253, 2003) que, exige a rentabilidade e sustentabilidade econômica. As palavras da Vice-Ministra de Água, Leyla Rojas, em 2009, deixam claro o entendimento da água e dos aquedutos na lógica do Estado:

'Nós [Estado], não temos o debate ideológico entre público e privado. Nosso debate é entre eficiência e ineficiência, porque as pessoas o que elas querem é a água, não importa quem a forneça. Devo dizer com toda a clareza e toda a responsabilidade do caso: a intenção é muito boa [converter o direito à água potável como um direito fundamental consagrado na Constituição], mas é perversa em termos de sustentabilidade do recurso. Porque a natureza dá a água porem imprópria para consumo, não a trata, nem opera, nem a mantém. São necessários recursos financeiros para sustentar a prestação de serviço de aqueducto. Entendo a intenção, mas onde é que vamos conseguir o dinheiro?”' (El Tiempo, 27 de março de 2009)

Os rumores sobre a implementação dos PDAs, em Puracé, em 2010, dividiram a opinião da comunidade. De um lado, estão aqueles que pouco questionam esses planos e acreditam ser necessário o acesso à água potável que eles prometem. Por outro lado, estão aqueles que têm receios, porque dizem que é um passo para a privatização da água e perda de autonomia territorial. Regionalmente, os Cabildos e prefeituras têm adotado posições favoraveis e contrárias à esses planos. O Cabildo Indígena de Puracé, está ciente dessa divisão de opiniões na comunidade. Têm escolhido a estratégia de sistematizar e informar sobre as vantagens e contras dos PDAs. Para o Cabildo, ficou claro que a sua posição era mais compatível com outro movimento, que se projetou no âmbito nacional, o referendo pela água, que propôs acrescentar a água como um bem comum e público na Constituição Política da Colômbia.

O Cabildo, por sua vez, desenvolveu uma proposta organizativa para a gestão autónoma da água que resultou em um híbrido entre uma empresa de serviços (de propriedade coletiva do Cabildo) e a atual organização comunal das veredas. As discussões, nesse ano, conduziram a repensá-la em termos de fortaleciemento da estrutura comunal atual colocando o Cabildo como uma instância reguladora dos abastecimentos de água nas veredas, no âmbito do Resguardo. Isso implica que a água não somente seja tratada como $\mathrm{H} 2 \mathrm{O}$ ou recurso hídrico, mas também como um ser com espírito que determina como construir as estruturas de capatação e distribuição de água. Do mesmo modo, os abastecimentos de água são baseados em princípios comunais, e não de rentabilidade ou sustentabilidade econômica. Finalmente, embora para muitos a idéia de água potável é importante, outros deixam em evidência que a comunidade sobreviveu, até agora, com essa água e questionam a necessidade da estação de tratamento de água.

\section{REFLEXÕES FINAIS}

Percorrer os abastecimentos de água, em Puracé, revelou que, nesse território, coexistem mundos diferentes que se conectam, neste caso, através da água. Assim, um abastecimento de água é uma rede que une mundos e, não 
somente, parte de um processo de modernização dos territórios indígenas.

Apesar das intervenções estatais e não-governamentais em Puracé que, entendem a água, somente, como o recurso natural $\left(\mathrm{H}_{2} \mathrm{O}\right.$, objeto) no RIP pode ser visto que, além de objeto, esse líquido tem espírito e vontade, influenciando de várias formas o modo de interagir com ele. Isto torna dificil definir se a comunidade Puraceña é moderna ou nãomoderna. Portanto, adotei à expressão não[tão]modernos para referir suas formas de saber e fazer ou as conexões com o mundo moderno, que se tornaram evidentes mediante os percursos pelos abastecimentos de água que, conectam hidrogênio, oxigênio, gravidade, o espírito da água, o duente, a organização indígena e as políticas públicas.

Esta coexistência aparentemente pacífica entre os mundos ocorre no território indígena, no tópos do Outro, ali a àgua pode ser múltipla. Para uma mãe puraceña, a água têm bactérias e espírito. Em Puracé, existe uma vocação de abertura ao pensamento e práticas forâneas, especialmente aquelas de especialistas (engenheiros, advogados, cientistas). Não se questiona nem a bruxo, nem ao cientista, a menos que proponham inconsistências em relação à causa organizativa.

Do percurso se deduz que o encontro entre os fluxos globais e os processos locais geram articulações com diferentes graus de desigualdade. No caso de Puracé, cabe perguntar se o espírito da água ficará relegado, somente, aos nascimentos e aos isolamentos reflorestados, onde se toma a àgua para os abastecimentos, e nas compilações míticas do tempo dos antigos. Ou será ator nos processos de tomada de decisões, da mesma forma como ocorre quando uma mãe puraceña passa perto de uma nascente com seu filho, retirando-o para que não se assuste.

Em Puracé, é evidente a ampliação de redes entre os mundos, mas este processo implica a inclusão hegemônica de saberes modernos (e.g, desenvolvimento sustentável)como o mais precisona definição das relações entre os humanos enão-humanos. Resta saber se esse momento de diversidade e experimentação é uma transição para a homogeneidade multicultural/mononatural ou se dará luzes para a criação de espaços ontológicos de negociação (Blaser, 2009; de la Cadena, 2009) ou cosmopolíticos (Latour, 2004a; Stengers, 2005). Morrerão os elementos dos mundos locais que não não se acoplem, coerentemente, com o mundo da ecologia e da economia global e somente viverão aqueles cuja tradução seja coerente com os princípios do mundo [pós] moderno?

Versão em português: Elizabeth Ruano

\section{BIBLIOGRAFIA}

AGRAWAL, Arun. Environmentality: Technologies of Government and the Making of Subjects. Durham: Duke University Press. 2005. 325 p.

ASHER, Kiran e OJEDA, Diana. "Producing nature and making the state: Ordenamiento territorial in the Pacific lowlands of Colombia”. Geoforum, 2009. n 40, pp. 292-302.

BARAD, Karen. “Agential Realism. Feminist interventions in understanding scientific practices”. In: BIAGIOLI, M. 
(org.) The science studies reader. New York: Routledge, 1999, pp. 1-11.

BLASER, Mario. 'La ontología política de un programa de caza sustentable”. WAN e-journal, 2009. n . 4. pp. 81-107.

CALDERÓN, Kenny. “Vida y muerte de los seres del agua. el Cacurí (Wairo)”. Maguaré 2010. n’. 24, pp. 173-194.

CARREIRA, Ana María. 'De las perturbadoras y conflictivas relaciones de los bogotanos con sus aguas”. Tabula Rasa, 2007.Vol. 6, pp. 263-285.

CAYON, Luis. “Ide Ma: el camino de agua espacio, chamanismo y persona entre los Makuna”. Antípoda. 2008. n.7, pp. 141-173.

CAYON, Luis. "En la búsqueda del orden cósmico: sobre el modelo de manejo ecológico Tukano oriental del Vaupés". Revista Colombiana de Antropología, 2001.Vol. 37, pp. 234-267.

COLÔMBIA. CONPES 3463. 2007. Planes departamentales de agua y saneamiento para el manejo empresarial de los servicios de acueducto, alcantarillado y aseo. Bogotá: Consejo Nacional de Política Económica y Social República de Colombia Departamento Nacional de Planeación. Ministerio de Ambiente, Vivienda y Desarrollo Territorial. 30p.

COLÔMBIA. CONPES 3253. 2003. Importancia estratégica del programa de modernización empresarial en el sector de agua potable y saneamiento básico. Bogotá: Consejo Nacional de Política Económica y Social República de Colombia Departamento Nacional de Planeación. Ministerio de Ambiente, Vivienda y Desarrollo Territorial. 13p.

COLÔMBIA. SIRAP Macizo Colombiano, sf. Sistema regional de áreas protegidas Bogotá: Parques Nacionales. 121 p.

COLÔMBIA. Constitución Política de Colombia. Bogotá: Congreso de la República. 1991.

COLÔMBIA. Ley 142 de 1994. Por la cual se establece el régimen de los servicios públicos domiciliarios y se dictan otras disposiciones. Bogotá: Congreso de Colombia. 1994.

COLÔMBIA. Ley 99 de 1993. Por la cual se crea el Ministerio del Medio Ambiente, se reordena el Sector Público encargado de la gestión y conservación del medio ambiente y los recursos naturales renovables, se organiza el Sistema Nacional Ambiental, SINA, y se dictan otras disposiciones. Bogotá: Congreso de Colombia. 1993.

CRIC. Cartilla de legislación indígena. Consejo Regional Indígena del Cauca, Popayán: CRIC. 2009. 248 p.

DE LA CADENA, Marisol. "Política indígena: un análisis más allá de 'la política”". WAN e-journal, 2009.n`. 4. pp. 139-171.

DESCOLA, Philippe. Par-delà nature et culture. Francia: Editions Gallimard. 2005.623 p. 
ESCOBAR,Arturo. Territorios de diferencia: Lugar, movimientos, vida, redes. Popayán: Envión Editores. 2010[2008]. $578 \mathrm{p}$.

FAUST, Franz. Un viaje por los paisajes míticos de Colombia. Popayán: Editorial Universidad del Cauca. 2004a 73 p.

FAUST, Franz. "La cosmovisión de los Cococnucos y los Yanaconas en su arquitectura”. Boletín de Antropología, 2004b, Vol. 18, n. 35, pp. 350-360.

FAUST, Franz. "Etnogeografía y etnogeología de Coconuco y Sotará”. Revista Colombiana de Antropología, 1990, Vol. 27, pp.54-90.

FERGUSON, James. Global shadows. Africa in the neoliberal world order. Durham: Duke University Press. 2006. $247 \mathrm{p}$.

GOW, David. Countering Development: Indigenous Modernity and the Moral Imagination. Durham: Duke University Press. 2008. 320 p.

LATOUR, Bruno. Reensamblar lo social: una introducción a la teoría del actor- red. Buenos Aires: Editorial Manantial. 2008.390 p.

LATOUR, Bruno. Nunca fuimos modernos. Ensayos de antropología simétrica. Buenos Aires: Siglo XXI editores. 2007[1991]. 224 p.

LATOUR, Bruno. Politiques de la nature. Comment faire entrer les sciences en démocratie. Paris: La Découverte. 2004a. [1999]. 383 p.

LATOUR, Bruno. Le rappel de la modernité - approches anthropologiques. Disponível em Ethnographiques. org, $\mathrm{n}^{\circ}$ 6. 2004b.(http://www.ethnographiques.org/2004/Latour.html)

LATOUR, Bruno. Guerre des mondes - offre de paix. Disponível em (http://www.bruno- latour.fr/sites/default/files/81GUERRE-PAIX-UNESCO-FR.pdf).

MARTINEZ-DUEÑAS, William. Cosmopolitismo ambiental y redes multinaturales: un recorrido por mundos no[tan]modernos en Puracé, Colombia. Tese de Doutorado em Antropología. Universidade de Cauca. 2012. 229 p.

PERAFÁN, Astrid. Tese de Doutorado em Antropologia. Universidade de Cauca. SD.

ROA, Tatiana e URREA, Danilo. Colombia: un referendo para dignificar el agua. Ecología Política, 2008, ñ. 36, pp. 124-126.

RODRÍGUEZ, César e ORDUZ, Natalia. Adiós río. La disputa por la tierra, el agua y los derechos indígenas en torno a la represa de Urrá. Bogotá: Centro de Estudios de Derecho, Justicia y Sociedad, Dejusticia. 2012. 188 p. 
ROVERE, Martha e IZA, Alejandro. Prácticas ancestrales y derecho de aguas: de la tensión a la coexistencia. Suiza: UICN, Gland. 2007. 159 p.

RUTHERFORD, Paul. Ecología, ciencia natural y biopolítica. Revista Mexicana de Sociología, 2000, Vol. 62, nº 3 , pp. 147-165.

STENGERS, Isabelle. “The cosmopolitical proposal”. In: LATOUR, B. e WEIBEL, P. (org.) Making things public. Atmospheres of democracy. Cambridge: MIT Press. 2005. pp. 994-1003.

TOCANCIPÁ FALLA, Jairo. 'El trueque: tradición, resistencia y fortalecimiento de la economía indígena en el Cauca". Revista de Estudios Sociales, 2008, n. 31, pp. 146- 161.

TROUILLOT, Michel-Rolph. “Anthropology and the savage slot: the poetics and politics of otherness”. In: FOX, R (org.) Recapturing anthropology. Santa Fe: SAR. 1991.pp. 17-44.

ULLOA, Astrid. La construcción del nativo ecológico. Complejidades, paradojas y dilemas de la relación entre los movimientos indígenas y el ambientalismo en Colombia. Bogotá: Instituto Colombiano de Antropología e Historia (ICANH) e COLCIENCIAS. 2004. 364 p.

VIVEIROS DECASTRO, Eduardo. “Perspectivismo y multinaturalismo en laAmérica Indígena”. In: SURRALLÉS, A. e GARCÍA,P.(org.). Tierraadentro: Territorio Indígenay Percepción delEntorno. Dinamarca:IWGIA. Copenhague. 2004. p. 37-80. 